\title{
EMMPRIN is associated with SIO0A4 and predicts patient outcome in colorectal cancer
}

\author{
K Boye ${ }^{*, 1,2}$, JM Nesland ${ }^{3,4}$, B Sandstad ${ }^{5}$, M Haugland Haugen', GM Mælandsmo ${ }^{1,6}$ and K Flatmark ${ }^{1,7}$ \\ 'Department of Tumour Biology, Institute for Cancer Research, The Norwegian Radium Hospital, Oslo University Hospital, PO Box 4953 Nydalen, NO-0424 \\ Oslo, Nonway; '2Department of Oncology, The Norwegian Radium Hospital, Oslo University Hospital, PO Box 4953 Nydalen, NO-0424 Oslo, Norway; \\ ${ }^{3}$ Department of Pathology, The Norwegian Radium Hospital, Oslo University Hospital, PO Box 4953 Nydalen, NO-0424 Oslo, Norway; ${ }^{4}$ Medical Faculty, \\ University of Oslo, PO Box 1078 Blindern, NO-0316 Oslo, Nonway; ${ }^{5}$ Unit of Biostatistics and Epidemiology, The Norwegian Radium Hospital, Oslo University \\ Hospital, PO Box 4953 Nydalen, NO-0424 Oslo, Nonway; ${ }^{6}$ Department of Pharmacy, Faculty of Health Sciences, University of Tromsø, NO-9037 Troms $\varnothing$, \\ Norway; ${ }^{7}$ Department of Surgical Oncology, The Norwegian Radium Hospital, Oslo University Hospital, PO Box 4953 Nydalen, NO-0424 Oslo, Norway
}

BACKGROUND: Proteolytic enzymes and their regulators have important biological roles in colorectal cancer by stimulating invasion and metastasis, which makes these factors attractive as potential prognostic biomarkers.

METHODS: The expression of extracellular matrix metalloproteinase inducer (EMMPRIN) was characterised using immunohistochemistry in primary tumours from a cohort of 277 prospectively recruited colorectal cancer patients, and associations with expression of SIOOA4, clinicopathological parameters and patient outcome were investigated.

RESULTS: One hundred and ninety-eight samples (72\%) displayed positive membrane staining of the tumour cells, whereas 10 cases (4\%) were borderline positive. EMMPRIN expression was associated with shorter metastasis-free, disease-specific and overall survival in both univariate and multivariate analyses. The prognostic impact was largely confined to TNM stage III, and EMMPRIN-negative stage III patients had an excellent prognosis. Furthermore, EMMPRIN was significantly associated with expression of SIO0A4, and the combined expression of these biomarkers conferred an even poorer prognosis. However, there was no evidence of direct regulation between the two proteins in the colorectal cancer cell lines HCTII6 and SW620 in siRNA knockdown experiments.

CONCLUSION: EMMPRIN is a promising prognostic biomarker in colorectal cancer, and our findings suggest that it could be used in the selection of stage III patients for adjuvant therapy.

British Journal of Cancer (2012) 1 07, 667-674. doi: I0.1038/bjc.2012.293 www.bjcancer.com

Published online 10 July 2012

(C) 2012 Cancer Research UK

Keywords: EMMPRIN; SI00A4; colorectal cancer; prognostic biomarker

The vast majority of patients who die from colorectal cancer succumb to metastatic disease (Cunningham et al, 2010). Improved detection strategies have resulted in patients being diagnosed at potentially curable disease stages, but despite adequate surgery and adjuvant therapy $20-30 \%$ of potentially cured patients experience disease recurrence, mainly in the form of distant metastases (O'Connell et al, 2004). To initiate growth in a secondary organ, tumour cells must complete a number of biological events, including local invasion of host stroma, intravasation, survival in the circulation, extravasation and proliferation at the metastatic site (Valastyan and Weinberg, 2011). Protease activity is required for several of these steps, and matrix metalloproteinases (MMPs) are among the key enzymes responsible for protease activity during the metastatic process (Egeblad and Werb, 2002). Elevated expression of several MMPs has been associated with poor outcome in colorectal cancer, including MMP-1, -2, -7, -9, -13 and -14. (Murray et al, 1996; Curran et al, 2004; Hilska et al, 2007; van der Jagt et al, 2009). Correspondingly, proteins that promote MMP activity are often associated with a proteolytic and pro-invasive phenotype,

*Correspondence: Dr K Boye, E-mail: kjetil.boye@rr-research.no Received 21 February 2012; revised II June 2012; accepted 13 June 2012; published online 10 July 2012 and overexpression of such proteins in primary tumours of cancer patients thus often confers a poor prognosis (van der Jagt et al, 2009).

One MMP-associated candidate biomarker is the metastasispromoting protein S100A4, and we recently demonstrated that nuclear expression of S100A4 was a robust prognostic factor in colorectal cancer (Boye et al, 2010). This small calcium-binding protein is involved in epithelial-mesenchymal transition and has been implicated in several steps of the metastatic cascade, including motility, invasion and angiogenesis (Boye and Mælandsmo, 2010). It stimulates the expression and activity of several MMPs (Bjørnland et al, 1999; Schmidt-Hansen et al, 2004; Saleem et al, 2006), and MMP activation is most likely critical for S100A4-induced metastasis, but the mechanisms involved in S100A4-mediated regulation of MMP activity and expression are largely unknown. Another key regulator of MMP activity in both stromal and tumour cells is the extracellular matrix metalloproteinase inducer (EMMPRIN/CD147/basigin) (Yan et al, 2005), a cell surface glycoprotein belonging to the immunoglobulin superfamily (Biswas et al, 1995). In experimental models, overexpression of EMMPRIN promotes tumour growth, invasion, angiogenesis and metastasis (Zucker et al, 2001; Tang et al, 2005). EMMPRIN is expressed in the majority of human tumour types, including colorectal cancer (Riethdorf et al, 2006; Li et al, 2009), and associations between EMMPRIN expression and poor 
prognosis have previously been shown in breast cancer (Reimers et al, 2004; Li et al, 2009), genitourinary carcinomas (Han et al, 2010) and non-small cell lung cancer (Sienel et al, 2008). In colorectal cancer, however, no large studies on patient outcome have been reported.

In the present work, associations between EMMPRIN expression, clinicopathological parameters and patient outcome were investigated in a cohort of prospectively recruited colorectal cancer patients undergoing curatively intended surgery. As EMMPRIN and S100A4 both modify the activity of a number of different MMPs, a reciprocal regulation could exist to induce a proteolytic and pro-invasive phenotype. To explore this possibility, expression data from this cohort were analysed for associations between expression of EMMPRIN and S100A4 in primary tumour samples, and functional studies were carried out in two colorectal cancer cell lines.

\section{MATERIALS AND METHODS}

\section{Patient cohort}

Between September 1998 and July 2000, 316 patients from five hospitals in the Oslo region were included in the study at the time of primary surgery for assumed or verified colorectal cancer (Flatmark et al, 2002). The study was approved by the Regional Ethics Committee (no. S-98080) and informed consent was obtained from the patients. Thirty-one patients were excluded for the following reasons: not invasive cancer (25), histology other than adenocarcinoma (5) and unknown stage of disease (1). The total study population thus consisted of 285 patients, and paraffin sections were available from 277 of these patients. For the prognostic studies, 43 patients were excluded due to distant metastases at the time of surgery (34), inadequate surgical margins (7) and preoperative chemoradiotherapy (2). The study population for the survival analyses thus included 242 patients in TNM stage I-III who had undergone curative surgery. The follow-up of the patient cohort has been described in detail previously (Boye et al, 2010). Briefly, patients were followed by physicians at the participating hospitals, and metastasis-free, disease-specific and overall survival was registered. In addition, survival data were obtained from the National Registry of Norway and updated by 1 October 2008. The cause of death was registered and classified as death from colorectal cancer, death of other causes or death of unknown cause. For overall survival, median follow-up of patients still alive was 9.1 years (range 8.2-10.0). Metastasis-free survival was defined as time to first metachronous distant metastasis, and patients without metastases were censored at time of death.

\section{Immunohistochemistry}

The primary tumour sections were re-evaluated by the study pathologist (JMN), and representative paraffin blocks for each tumour were identified for subsequent immunohistochemical analysis. Immunohistochemistry was performed using the biotin-streptavidin-peroxidase method (Supersensitive Immunodetection System, LP000-UL; Biogenex, San Ramon, CA, USA) and the Optimax Plus Automated Cell Staining System (Biogenex). After treatment with $1 \%$ hydrogen peroxide for $10 \mathrm{~min}$ to block endogenous peroxidase, the sections were incubated with goat polyclonal anti-EMMPRIN antibody (sc-9752; Santa Cruz Biotechnology, Santa Cruz, CA, USA), diluted $1: 300$, for $30 \mathrm{~min}$ at room temperature. The sections were then incubated with biotin-labelled secondary antibody $(1: 30)$ and streptavidin-peroxidase $(1: 30)$ for $20 \mathrm{~min}$ each. Slides were stained for $5 \mathrm{~min}$ with $0.05 \% 3,3^{\prime}$ diaminobenzidine tetrahydrochloride freshly prepared in $0.05 \mathrm{M}$ Tris- $\mathrm{HCl}$ buffer ( $\mathrm{pH} 7.6$ ) containing $0.024 \%$ hydrogen peroxide and then counterstained with haematoxylin, dehydrated, and mounted in Diatex. The dilutions were made with phosphatebuffered saline, $\mathrm{pH} 7.4$, containing $1 \%$ bovine serum albumin. EMMPRIN-negative cell types in each section served as negative control, and in addition negative controls with omission of the primary antibody were performed. As positive controls, tissues with known expression of EMMPRIN were applied. Cytoplasmic and membrane staining were recorded as separate variables, and the number of EMMPRIN-positive tumour cells was semiquantitatively estimated and graded from 0 to 5 (percentage of positive carcinoma cells in parentheses): $0(0 \%), 1(1-4 \%), 2$ $(5-9 \%), 3(10-14 \%), 4(15-49 \%)$ and $5(>50 \%)$. For all statistical analyses, tumours in grade $2-5$ were grouped as positive. Classifying the borderline positive tumours (1-4\% positive tumour cells) as positive did not significantly affect the univariate survival analyses or the associations with other clinicopathological variables. Expression of EMMPRIN in stromal cells or neighbouring non-malignant epithelium was not systematically assessed.

\section{Statistical analysis}

Associations between EMMPRIN staining and clinicopathological variables were tested using two-tailed Fisher's exact test or linearby-linear association $\chi^{2}$ test. Univariate survival analysis was performed according to the Kaplan-Meier method, and survival was compared using the log-rank test. Multivariate analysis was conducted using the Cox proportional hazards regression model with backward, stepwise elimination of variables. Survival was measured from date of surgery until death for overall and diseasespecific survival, and from date of surgery until diagnosis of distant metastasis for metastasis-free survival. Data analysis was performed using SPSS version 16.0 (SPSS Inc., Chicago, IL, USA). $P$-values $<0.05$ were considered statistically significant.

\section{Cell culture and treatment}

The human colorectal cancer cell lines HCT116 and SW620 were purchased from the American Type Culture Collection (Rockville, MD, USA). All cell cultures were routinely tested for Mycoplasma infection, and the identity of the cell lines was verified by STR profiling using Powerplex 16 (Promega, Madison, WI, USA). Cells were cultivated in RPMI 1640 (BioWhittaker, Lonza Verviers, Belgium), supplemented with $8.5 \%$ heat-inactivated fetal calf serum (PAA, New Bedford, MA, USA), 20 mm Hepes (BioWhittaker) and 2 mm Glutamax (Gibco, Invitrogen, Carlsbad, CA, USA). For experiments with extracellular S100A4, cells were seeded at $1.2 \times 10^{5} \mathrm{~cm}^{-2}$ in T25-flasks and allowed to attach overnight. Fresh cell culture medium with or without $10 \mu \mathrm{g} \mathrm{ml}^{-1}$ human recombinant S100A4 was added, and the cells were further incubated for 24 or $48 \mathrm{~h}$ before being harvested by scraping in ice-cold PBS. Production of recombinant S100A4 has been described previously (Berge et al, 2011).

\section{siRNA transfection}

Cells were seeded at $2.0 \times 10^{4} \mathrm{~cm}^{-2}$ in T25-flasks and allowed to attach overnight. siRNA constructs were mixed with Lipofectamine 2000 (Invitrogen) for $20 \mathrm{~min}$ at room temperature in Opti-MEM I and added to the cell cultures at a final concentration of $50 \mathrm{nM}$. After incubation for $24 \mathrm{~h}$ cell culture medium with the transfection mixture was removed and replaced with fresh cell culture medium. Cells were incubated for another $48 \mathrm{~h}$ and then harvested by scraping in ice-cold PBS. siRNA constructs used were as follows: Silencer Select Negative Control no. 2 siRNA (Ambion/Applied Biosystems, Austin, TX, USA), S100A4 siRNA (Boe et al, 2007) and Silencer Pre-designed siRNA ID215973 (siEMMPRIN1), ID147251 (siEMMPRIN2) and ID10372 (siEMMPRIN3) (Ambion). 


\section{Protein isolation and western blotting}

Cell lysates were prepared as described previously (Grotterød et al, 2010). Total protein lysates were separated on $4-12 \%$ NuPAGE Novex Bis-Tris Gels (Invitrogen) in MES buffer and transferred to Immobilon-P membranes (Millipore, Bedford, MA, USA). As a transfer and loading control, membranes were stained with $0.1 \%$ amidoblack. Tris-buffered saline containing $0.1 \%$ Tween 20 and $5 \%$ non-fat dry milk was used for all incubations. After $1 \mathrm{~h}$ blockage of non-specific binding sites, membranes were incubated for $1 \mathrm{~h}$ at room temperature or overnight at $4{ }^{\circ} \mathrm{C}$ with mouse anti-S100A4 22.3 diluted 1:1000 (Flatmark et al, 2004), goat anti-EMMPRIN diluted 1:500 (sc-9753; Santa Cruz Biotechnology) or mouse anti- $\alpha$ tubulin (1:1000; Calbiochem, Darmstadt, Germany). After washing, the membranes were incubated for $1 \mathrm{~h}$ at room temperature with horseradish peroxidise-conjugated secondary antibody (DAKO, Glostrup, Denmark) diluted 1:5000. Signals were visualised using Super Signal West Dura Extended Duration Substrate (Thermo Scientific, Waltham, MA, USA) and analysed using G:BOX (Syngene, Frederick, MD, USA) with the GeneSnap software (Syngene).

\section{RESULTS}

\section{EMMPRIN protein expression in primary colorectal adenocarcinomas}

The expression of EMMPRIN was analysed by immunohistochemistry in primary tumours from a prospectively recruited cohort of 277 colorectal cancer patients. In tumour cells, staining was observed both in the cytoplasm and on the cell membrane (Figure 1). Varying degrees of membrane expression was detected in 208 samples $(75 \%)$, of which 10 cases $(4 \%)$ were borderline positive ( $<5 \%$ positive tumour cells) and 250 samples $(91 \%)$ displayed cytoplasmic staining (Table 1). As expected, a highly significant association between EMMPRIN expression in the cytoplasm and the membrane was observed $(P<0.001)$. As the presently known biological function of EMMPRIN is mainly confined to the cell membrane, only membrane staining was considered positive and used for further analyses.

\section{Associations between EMMPRIN expression and clinicopathological parameters}

The clinical and histopathological baseline data of the study cohort are presented in Table 2 . Mean age at the time of surgery was 70 years (range 21-98 years). Sixty-eight percent of the tumours were localised in the colon and $32 \%$ in the rectum. The majority of patients were in early disease stages, with $19 \%$ in TNM stage I, $40 \%$ in stage II, $30 \%$ in stage III and $12 \%$ in stage IV. There were no statistically significant associations between EMMPRIN expression and any of the clinical or histopathological parameters (Supplementary Table 1).

\section{EMMPRIN expression and patient outcome}

For the survival analyses, only patients in TNM stage I-III that had undergone R0 resections were included, resulting in a study population of 242 patients. The clinicopathological data and outcome parameters of this cohort have been described previously (Boye et al, 2010). Using a cut-off value of $5 \%$ positive tumour cells, EMMPRIN expression was a highly significant predictor of metastasis-free survival (Figure 2A), and the 5-year metastasis-free survival rate of patients with EMMPRIN-negative tumours was $87 \%$, compared with $63 \%$ for patients with EMMPRIN-positive tumours. EMMPRIN expression was also associated with disease-specific survival (Figure 2B), whereas the association with overall survival was not statistically significant (Figure 2C). To determine whether the relationship between EMMPRIN expression and patient outcome was influenced by other clinical and histopathological parameters, multivariate Cox regression analysis was performed. Variables included in the multivariate analysis were EMMPRIN, age, gender, TNM stage, differentiation, tumour localisation, lymphocyte infiltration, vascular invasion and perineural invasion. Remarkably, EMMPRIN expression was the most significant predictor of metastasis-free survival (Table 3). EMMPRIN was also an independent prognostic factor for disease-specific survival $(P=0.04$; hazard ratio 2.3; 95\% confidence interval (CI) 1.0-5.0; data not shown), but not statistically significant for overall survival $(P=0.07$; hazard ratio 1.5 ; 95\% CI 1.0-2.5; data not shown).

\section{Prognostic impact of EMMPRIN expression in TNM stage III}

To investigate the prognostic impact of EMMPRIN expression in the separate disease stages, patients were stratified according to TNM stage, and univariate survival analyses were performed. In TNM stage III, EMMPRIN was strongly associated with patient outcome (Figure 2F), whereas no prognostic significance was observed in TNM stage I and II (Figures 2D and E). In fact, only 2 of $21(9.5 \%)$

Table I Immunohistochemical expression of EMMPRIN

\begin{tabular}{lcc}
\hline & $\begin{array}{c}\text { Membrane staining } \\
\text { Number }\end{array}$ & $\begin{array}{c}\text { Cytoplasmic staining } \\
\text { Number }\end{array}$ \\
\hline 0 & $68(25)$ & $26(9)$ \\
1 & $10(4)$ & $0(0)$ \\
2 & $19(7)$ & $11(4)$ \\
3 & $41(15)$ & $33(12)$ \\
4 & $70(25)$ & $67(24)$ \\
5 & $68(25)$ & $139(50)$ \\
ND & 1 & 1
\end{tabular}

Abbreviations: EMMPRIN = extracellular matrix metalloproteinase inducer; ND = not determined. ${ }^{a} \mathrm{~A}$ total of 277 samples were examined.
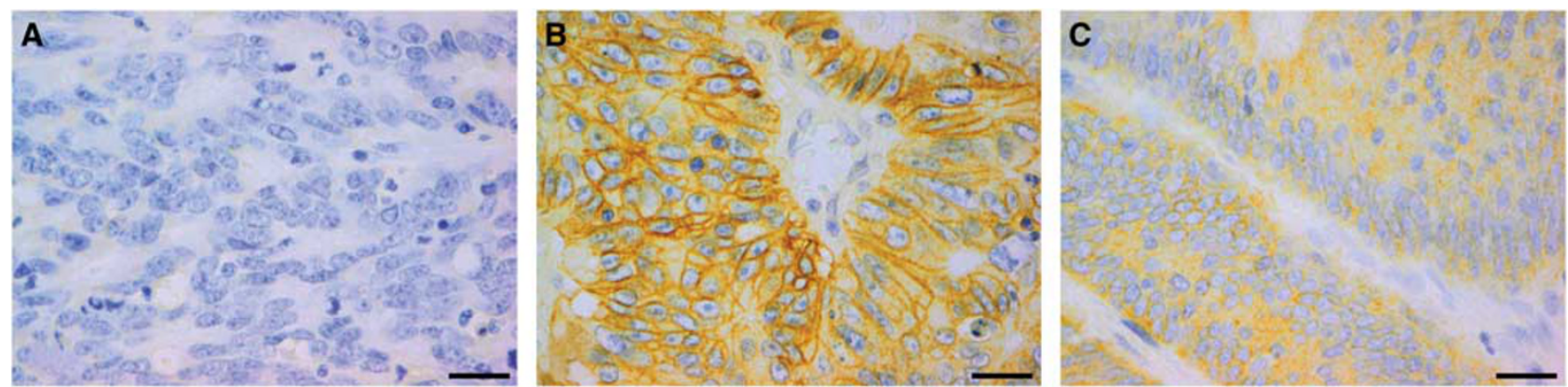

Figure I Representative photomicrographs of immunohistochemical staining of colorectal cancer specimens with anti-EMMPRIN antibody. (A) No immunoreactivity. (B) Strong cytoplasmic and membrane staining (score 5). (C) Strong cytoplasmic staining (score 5) and no membrane staining (score 0). Scale bar $=20 \mu \mathrm{m}$. 
Table 2 Baseline clinical and histopathological data of the study cohort

\begin{tabular}{|c|c|c|}
\hline \multirow[b]{2}{*}{ Parameter } & \multicolumn{2}{|c|}{ Patients $^{\mathrm{a}}$} \\
\hline & Number & $\%$ \\
\hline \multicolumn{3}{|l|}{ Gender } \\
\hline Female & 130 & 47 \\
\hline Male & 147 & 53 \\
\hline \multicolumn{3}{|l|}{ TNM stage } \\
\hline 1 & 52 & 19 \\
\hline ॥ & 111 & 40 \\
\hline III & 82 & 30 \\
\hline IV & 32 & 12 \\
\hline \multicolumn{3}{|l|}{ pT } \\
\hline । & 8 & 3 \\
\hline 2 & 51 & 19 \\
\hline 3 & 179 & 65 \\
\hline 4 & 37 & 13 \\
\hline ND & 2 & \\
\hline \multicolumn{3}{|l|}{$\mathrm{pN}$} \\
\hline 0 & 166 & 60 \\
\hline 1 & 64 & 23 \\
\hline 2 & 45 & 16 \\
\hline ND & 2 & \\
\hline \multicolumn{3}{|l|}{ Differentiation } \\
\hline Well & 7 & 3 \\
\hline Intermediate & 229 & 83 \\
\hline Poor & 40 & 14 \\
\hline ND & I & \\
\hline \multicolumn{3}{|c|}{ Tumour localisation } \\
\hline Colon & 188 & 68 \\
\hline Rectum & 89 & 32 \\
\hline \multicolumn{3}{|c|}{ Lymphocyte infiltration } \\
\hline High & 32 & 12 \\
\hline Intermediate & 175 & 64 \\
\hline Low & 65 & 24 \\
\hline ND & 5 & \\
\hline \multicolumn{3}{|l|}{ Vascular invasion } \\
\hline Present & 62 & 23 \\
\hline Absent & 212 & 77 \\
\hline ND & 3 & \\
\hline \multicolumn{3}{|c|}{ Perineural invasion } \\
\hline Present & 29 & 11 \\
\hline Absent & 245 & 89 \\
\hline ND & 3 & \\
\hline \multicolumn{3}{|l|}{ Perinodal growth ${ }^{b}$} \\
\hline Present & 66 & 61 \\
\hline Absent & 43 & 39 \\
\hline
\end{tabular}

Abbreviations: $N D=$ not determined; $p N$ stage = pathological nodal stage; $\mathrm{pT}$ stage $=$ pathological tumour stage; $\mathrm{TNM}$ stage $=$ tumour node metastasis stage. ${ }^{\mathrm{a}} \mathrm{A}$ total of 277 patients were examined. berinodal growth was assessed in node positive patients only.

EMMPRIN-negative stage III patients developed distant metastasis, whereas 28 of 55 (51\%) of EMMPRIN-positive stage III patients did. For the TNM stage III patients, there were no associations between EMMPRIN expression and $\mathrm{pN}$ status $(P=0.29)$, perinodal growth $(P=0.80)$ or administration of adjuvant chemotherapy $(P=0.61)$, indicating that the prognostic impact of EMMPRIN in this patient group is not confounded by other variables.

\section{EMMPRIN and S100A4}

We have previously demonstrated that nuclear expression of the metastasis-associated protein S100A4 was a prognostic biomarker in the same patient cohort (Boye et al, 2010), and when the expression of the two biomarkers was combined, an even more pronounced survival difference was observed (Figure 3A). For EMMPRIN- and S100A4-negative patients, the estimated 5-year metastasis-free survival rate was $86 \%$, compared with $36 \%$ for patients with EMMPRIN- and S100A4-positive tumours $(P<0.0001)$. Estimated 10 -year overall survival rate was $68 \%$ and $24 \%$, respectively ( $P=0.001$; data not shown). Combined expression of both proteins was also significantly associated with poor metastasis-free survival in multivariate analysis $(P=0.002$, hazard ratio 5.8; 95\% CI 1.9-17.5; data not shown).

Interestingly, EMMPRIN expression was significantly associated with cytoplasmic expression of S100A4 $(P<0.001)$. Seventy-one percent of EMMPRIN-positive cases were S100A4-positive, whereas only $47 \%$ of EMMPRIN-negative tumours expressed S100A4 (Table 4). These results could indicate a direct regulation between S100A4 and EMMPRIN, and to investigate this hypothesis we downregulated the expression of both proteins using siRNA transfection in two colorectal carcinoma cell lines. Figure 3 shows that siRNA against EMMPRIN (B) and S100A4 (C) suppressed expression of the target protein. However, no regulation of S100A4 was observed in siEMMPRIN-transfected cells, and no regulation of EMMPRIN was seen in siS100A4-transfected cells. These data are further substantiated by investigations in HCT116 and SW620 cells stably transduced with shRNA against S100A4, where no changes in EMMPRIN expression levels were observed (data not shown). As S100A4 is present in the extracellular space, we also investigated whether treatment with recombinant S100A4 could affect EMMPRIN expression levels. Figure 3D clearly demonstrates that extracellular S100A4 did not alter EMMPRIN expression significantly. Taken together, these results show that expression of S100A4 and EMMPRIN is strongly associated in tumours from colorectal cancer patients, but no direct regulation between these proteins was evident in the two cell lines investigated.

\section{DISCUSSION}

In colorectal cancer there is a need for improved disease classification algorithms to predict outcome and to make optimal therapeutic decisions. Molecular biomarkers hold great promise to fulfil this need, and numerous investigations have been performed over the last years to identify such novel prognostic and predictive factors. Prognostic biomarkers could be identified through several approaches, of which high-throughput methods such as gene expression arrays or proteomics have been frequently employed. Such unbiased approaches have several advantages, but are generally hampered by the lack of functional data to understand the mechanisms involved. We have undertaken a biology-based approach, where we have investigated several proteins directly implicated in the metastatic process using immunhistochemistry, and analysed associations between expression data, clinicopathological parameters and patient outcome (Boye et al, 2010; Ingebrigtsen et al, 2012; Haugen et al, in preparation).

In this study, we report for the first time in a large cohort of prospectively recruited patients that expression of the MMPinducer EMMPRIN is associated with poor outcome in colorectal cancer. The 5-year metastasis-free survival rate for patients with EMMPRIN-negative tumours was $87 \%$ compared with $63 \%$ for EMMPRIN-positive patients, and EMMPRIN was also a predictor of metastasis-free survival in multivariate analysis. Furthermore, 49 of the 55 patients that developed distant metastasis had EMMPRIN-positive tumours, resulting in a sensitivity for prediction of metastastic disease of $89 \%$. The specificity, however, was rather low (32\%). By combining EMMPRIN expression with nuclear expression of S100A4, a previously identified prognostic biomarker in this patient cohort, we observed that the prognosis for patients with expression of both biomarkers was very poor. 
A

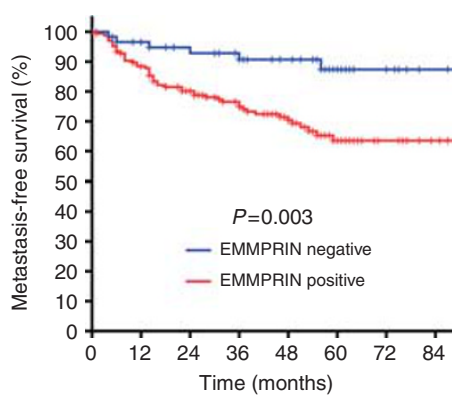

No. at risk:

Time (months)

EMMPRIN negative $\begin{array}{llllllll}64 & 54 & 49 & 44 & 32 & 19 & 9 & 3\end{array}$ EMMPRIN positive $\begin{array}{lllllllll}173 & 142 & 118 & 95 & 70 & 33 & 10 & 4\end{array}$

D

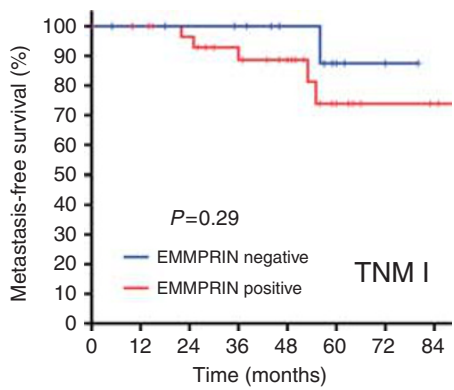

No. at risk:

$\begin{array}{lllllllll}\text { EMMPRIN negative } & 18 & 14 & 13 & 12 & 8 & 5 & 2 & 0\end{array}$

$\begin{array}{lllllllll}\text { EMMPRIN positive } & 34 & 31 & 27 & 22 & 17 & 8 & 3 & 2\end{array}$
B

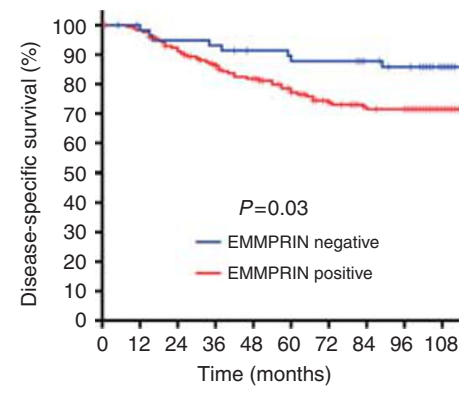

EMMPRIN negative $\begin{array}{llllllllll}64 & 55 & 54 & 51 & 50 & 49 & 45 & 42 & 23\end{array}$ EMMPRIN positive $1731671541401291171059593 \quad 46$
C

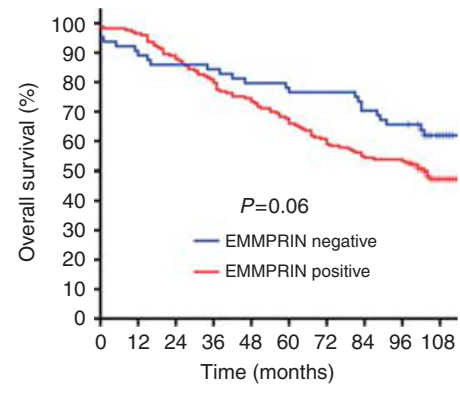

No. at risk:

EMMPRIN negative $\begin{array}{llllllllll}64 & 58 & 55 & 54 & 51 & 50 & 49 & 45 & 42 & 23\end{array}$ EMMPRIN positive $1731671541401291171059593 \quad 46$
E

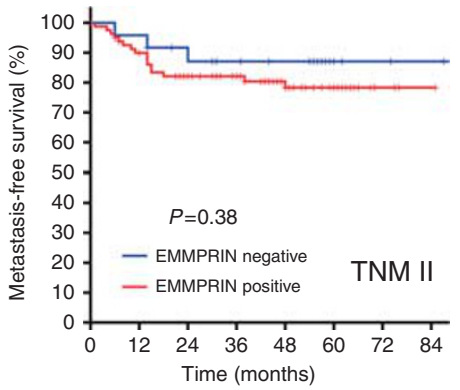

No. at risk:

EMMPRIN negative $\begin{array}{llllllll}25 & 23 & 20 & 17 & 14 & 7 & 4 & 3\end{array}$
$\mathbf{F}$

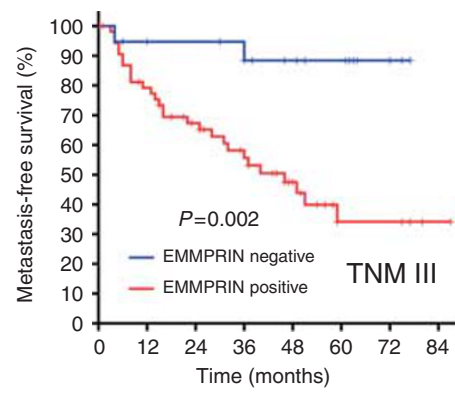

No. at risk:

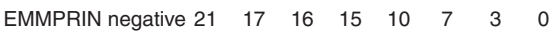
EMMPRIN positive $\begin{array}{lllllllll}55 & 41 & 31 & 23 & 14 & 4 & 4 & 1\end{array}$

Figure 2 Kaplan-Meier survival plots depicting metastasis-free $(\mathbf{A})$, disease-specific $(\mathbf{B})$ and overall survival (C) based on EMMPRIN expression. (D-F) Kaplan-Meier survival plots depicting metastasis-free survival stratified according to TNM stage and based on expression of EMMPRIN.

Table 3 Multivariate Cox regression analysis of metastasis-free survival ${ }^{a}$

\begin{tabular}{|c|c|c|c|}
\hline & $P$-value & Hazard Ratio & $95 \% \mathrm{Cl}$ \\
\hline $\begin{array}{l}\text { EMMPRIN } \\
0-1\end{array}$ & 0.008 & & \\
\hline $2-5$ & & 3.3 & 1.4-7.8 \\
\hline $\begin{array}{l}\text { Lymphocyte infiltration } \\
\text { High }\end{array}$ & 0.01 & & \\
\hline Intermediate & & 3.2 & $0.7-13.4$ \\
\hline Low & & 5.8 & 1.3-25.5 \\
\hline $\begin{array}{l}\text { TNM stage } \\
\text { । }\end{array}$ & 0.02 & & \\
\hline$\|$ & & 1.5 & $0.6-3.8$ \\
\hline III & & 2.9 & 1.2-7.4 \\
\hline $\begin{array}{l}\text { Tumour localisation } \\
\text { Colon }\end{array}$ & 0.06 & & \\
\hline Rectum & & 1.8 & $0.9-3.3$ \\
\hline $\begin{array}{l}\text { Differentiation } \\
\text { Well }\end{array}$ & 0.08 & & \\
\hline Intermediate & & 0.6 & $0.08-4.7$ \\
\hline Poor & & 1.6 & $0.2-13.4$ \\
\hline $\begin{array}{l}\text { Vascular invasion } \\
\text { Absent }\end{array}$ & 0.08 & & \\
\hline Present & & 1.7 & $0.9-3.3$ \\
\hline
\end{tabular}

Still, the clinical impact of the combined expression is rather modest compared with EMMPRIN expression alone, with a sensitivity of $93 \%$ and a specificity of $21 \%$ for expression of at least one biomarker, and $40 \%$ and $14 \%$, respectively, for expression of both proteins. Taken together, the major clinical significance of our findings seems to be that EMMPRIN-negative patients rarely experienced disease recurrence. In particular, EMMPRIN-negative stage III patients had a remarkably good prognosis, and only 2 of 21 patients in this group developed distant metastasis. Stage III patients are routinely offered adjuvant chemotherapy to reduce the risk of disease progression, even though $\sim 40 \%$ are cured by surgery alone (Laurie et al, 1989; Moertel et al, 1990). Thus, the discovery of a biomarker to identify low-risk stage III disease would spare these patients the morbidity and mortality associated with adjuvant chemotherapy, and our results indicate that EMMPRIN expression, if validated in future studies, could be used in the selection of patients for adjuvant treatment.

Several previous investigations have examined the expression of EMMPRIN in colorectal cancer (Jin et al, 2006; Riethdorf et al, 2006; Buergy et al, 2009; Zheng et al, 2011). In most reports, the majority of cases show some degree of EMMPRIN immunoreactivity, both in the cytoplasm and at the cell membrane, but different scoring systems preclude direct comparisons. To our knowledge, only two studies have explored the relationship between EMMPRIN expression and patient outcome (Buergy et al, 2009; Jung et al, 2011). Buergy et al (2009) found that a relative increase in EMMPRIN expression in the tumour compared with normal epithelium was associated with poor disease-specific survival in a cohort of 40 colorectal cancer patients from all disease stages. In contrast, EMMPRIN expression was not a prognostic factor in a retrospective study including 210 patients (Jung et al, 2011). However, overall survival was the only outcome measure reported, and the lack of complete follow-up data in addition to the retrospective recruitment of cases might explain the discrepant results.

In addition to its expression in the majority of primary tumours, EMMPRIN is frequently expressed in disseminated tumour cells (DTCs) isolated from bone marrow from breast, prostate and lung cancer patients (Klein et al, 2002; Reimers et al, 2004). In a panel of 38 colorectal cancer patients, EMMPRIN-positive tumour cells in 
A

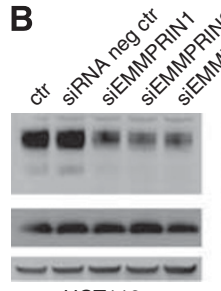

HCT116

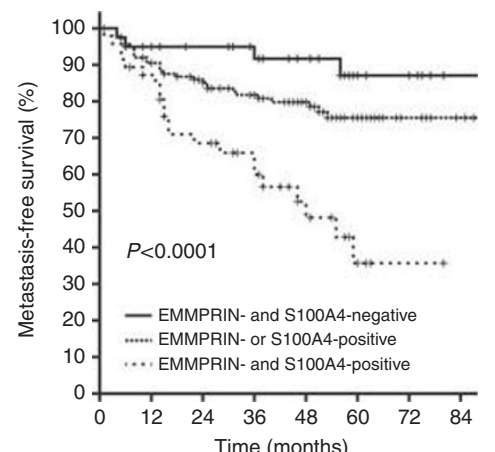

No. at risk: EMMPRIN- and $\begin{array}{lllllllll}\text { S100A4N-negative } & 43 & 35 & 32 & 29 & 22 & 13 & 7 & 1\end{array}$ $\begin{array}{lllllllll}\text { S100A4N-positive } & 147 & 122 & 107 & 88 & 68 & 34 & 11 & 6\end{array}$ EMMPRIN- and S100A4N-positive $\begin{array}{llllllll}47 & 39 & 28 & 22 & 12 & 5 & 1 & 0\end{array}$

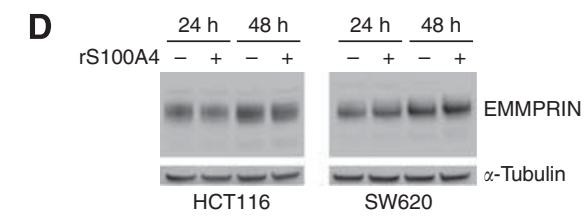

Figure 3 (A) Kaplan-Meier survival plot depicting metastasis-free survival based on expression of EMMPRIN and/or SIOOA4 as indicated. (B) Immunoblot of total cell lysates from HCTII6 and SW620 control cells (lane I in each panel), cells transfected with siRNA negative control (lane 2) or siRNA against EMMPRIN (lanes 3-5). Membranes were stained with anti-EMMPRIN and anti-SIO0A4. $\alpha$-Tubulin was used as a loading control. (C) Immunoblot of total cell lysates from HCTII6 and SW620 cells transfected with siRNA negative control (lanes I and 3) or siRNA against SI00A4 (lanes 2 and 4 ). Membranes were stained with antiEMMPRIN and anti-SIO0A4. $\alpha$-Tubulin was used as a loading control. The differences in molecular weight of EMMPRIN are due to glycosylation. (D) Immunoblot of total cell lysates from HCTII6 and SW620 cells treated with $10 \mu \mathrm{g} \mathrm{ml}^{-1}$ recombinant SI00A4 for 24 or $48 \mathrm{~h}$ as indicated. Membranes were stained with anti-EMMPRIN and $\alpha$-tubulin was used as a loading control. All results shown are representative of at least three independent experiments.

the bone marrow were identified in 11 cases, and interestingly, EMMPRIN-expressing cells were found in four of five patients with synchronous metastases (Buergy et al, 2009). In our patient cohort, the presence of DTCs analysed by immunocytochemistry (using an anti-cytokeratin antibody) and immunomagnetic selection (using an anti-EpCAM antibody) was an adverse prognostic factor (Flatmark et al, 2011). As both EMMPRIN expression in the primary tumour, the presence of DTCs and EMMPRIN expression in DTCs seem to be associated with metastatic disease in colorectal cancer, one might speculate that DTCs would be detected more frequently in patients with EMMPRIN-expressing primary tumours. However, no association was found between EMMPRIN expression and the presence of tumour cells in bone marrow in our cohort (DTCs were detected in $29 \%$ and $27 \%$ of EMMPRINnegative and -positive patients, respectively; data not shown).
Table 4 Immunohistochemical expression of EMMPRIN and SI00A4 $4^{\mathrm{a}}$

\begin{tabular}{lrr}
\hline & \multicolumn{3}{c}{ SI00A4 } \\
\cline { 2 - 3 } & Negative & Positive \\
\hline EMMPRIN & & \\
Negative & $41(53 \%)$ & $37(47 \%)$ \\
Positive & $57(29 \%)$ & $141(71 \%)$ \\
\hline
\end{tabular}

Abbreviation: EMMPRIN = extracellular matrix metalloproteinase inducer. ${ }^{2}$ The number (and percentages) of patients within each category is shown. ${ }^{b}$ Expression of cytoplasmic SI00A4.

Similar findings have been reported for breast cancer (Reimers et al, 2004), suggesting that the DTC detection methods employed are not able to identify all relevant DTCs. Indeed, DTCs were found in only 21 of the 55 patients that developed metastatic disease in our study.

As both EMMPRIN and S100A4 stimulate MMP activity, we investigated the associations between expression of these metastasis-related proteins in the primary tumour samples. Interestingly, a highly significant association was observed, and nearly three quarters of the EMMPRIN-positive tumours were also S100A4-positive. These results suggest that a reciprocal regulation between S100A4 and EMMPRIN could exist. Further supporting this hypothesis are previous findings that EMMPRIN positively regulates the $\mathrm{Wnt} / \beta$-catenin pathway (Sidhu et al, 2010), providing a possible mechanism for direct regulation of S100A4 (Stein et al, 2006). Similarly, EMMPRIN expression could be regulated by the S100A4 receptor RAGE (receptor for advanced glycation end products) (Bao et al, 2010) and the NF- $\kappa \mathrm{B}$ signalling pathway (Hagemann et al, 2005), which is also activated by S100A4 (Boye et al, 2008). However, there was no evidence of any direct regulation between EMMPRIN and S100A4 in the two colorectal cancer cell lines investigated. These findings could indicate that the expression of both proteins is regulated in the same manner, that is, controlled by the same signalling pathways or transcription factors, resulting in their presence in tumour cells of a proteolytic and pro-invasive phenotype, associated with a dismal prognosis.

In conclusion, EMMPRIN expression in primary colorectal adenocarcinomas was a robust prognostic factor in this patient cohort, and patients in all disease stages with EMMPRIN-negative tumours had an excellent prognosis. Future studies should focus on validation of EMMPRIN as a biomarker to select stage III patients for adjuvant chemotherapy.

\section{ACKNOWLEDGEMENTS}

We acknowledge the contributions of members of the Study Group for Bone Marrow Micrometastases in Colorectal Cancer: Øystein Fodstad, The Norwegian Radium Hospital (Study Group Leader); Hans Olaf Johannessen, Ullevål University Hospital (local study coordinator); Ida Bukholm, Akershus University Hospital (local study coordinator); Rocio Rosales, Asker and Bærum Hospital (local study coordinator); Lisbeth Hårklau, Aker University Hospital (local study coordinator); Hedin Jacobsen, Diakonhjemmet Hospital (local study coordinator). We also wish to thank Ellen Hellesylt and Solveig Pettersen for excellent technical assistance and Dr Sigurd Bøe for providing the S100A4 siRNA construct. This work was supported by the Norwegian Cancer Society (grant no. 574826 to KF and grant no. 421852 to GMM) and the Research Council of Norway (grant no. 193375/V50 to GMM).

Supplementary Information accompanies the paper on British Journal of Cancer website (http://www.nature.com/bjc) 


\section{REFERENCES}

Bao W, Min D, Twigg SM, Shackel NA, Warner FJ, Yue DK, McLennan SV (2010) Monocyte CD147 is induced by advanced glycation end products and high glucose concentration: possible role in diabetic complications. Am J Physiol Cell Physiol 299: C1212-C1219

Berge G, Pettersen S, Grotterød I, Bettum IJ, Boye K, Mælandsmo GM (2011) Osteopontin-an important downstream effector of S100A4mediated invasion and metastasis. Int J Cancer 129: 780-790

Biswas C, Zhang Y, DeCastro R, Guo H, Nakamura T, Kataoka H, Nabeshima K (1995) The human tumor cell-derived collagenase stimulatory factor (renamed EMMPRIN) is a member of the immunoglobulin superfamily. Cancer Res 55: 434-439

Bjørnland K, Winberg JO, Odegaard OT, Hovig E, Loennechen T, Aasen AO, Fodstad O, Mælandsmo GM (1999) S100A4 involvement in metastasis: deregulation of matrix metalloproteinases and tissue inhibitors of matrix metalloproteinases in osteosarcoma cells transfected with an anti-S100A4 ribozyme. Cancer Res 59: 4702-4708

Boe S, Longva AS, Hovig E (2007) Photochemically induced gene silencing using small interfering RNA molecules in combination with lipid carriers. Oligonucleotides 17: 166-173

Boye K, Grotterød I, Aasheim HC, Hovig E, Mælandsmo GM (2008) Activation of NF-kappaB by extracellular S100A4: analysis of signal transduction mechanisms and identification of target genes. Int J Cancer 123: $1301-1310$

Boye K, Mælandsmo GM (2010) S100A4 and metastasis: a small actor playing many roles. Am J Pathol 176: 528-535

Boye K, Nesland JM, Sandstad B, Mælandsmo GM, Flatmark K (2010) Nuclear S100A4 is a novel prognostic marker in colorectal cancer. Eur J Cancer 46: 2919-2925

Buergy D, Fuchs T, Kambakamba P, Mudduluru G, Maurer G, Post S, Tang Y, Nakada MT, Yan L, Allgayer H (2009) Prognostic impact of extracellular matrix metalloprotease inducer: immunohistochemical analyses of colorectal tumors and immunocytochemical screening of disseminated tumor cells in bone marrow from patients with gastrointestinal cancer. Cancer 115: 4667-4678

Cunningham D, Atkin W, Lenz HJ, Lynch HT, Minsky B, Nordlinger B, Starling N (2010) Colorectal cancer. Lancet 375: 1030-1047

Curran S, Dundas SR, Buxton J, Leeman MF, Ramsay R, Murray GI (2004) Matrix metalloproteinase/tissue inhibitors of matrix metalloproteinase phenotype identifies poor prognosis colorectal cancers. Clin Cancer Res 10: $8229-8234$

Egeblad M, Werb Z (2002) New functions for the matrix metalloproteinases in cancer progression. Nat Rev Cancer 2: 161-174

Flatmark K, Bjørnland K, Johannessen HO, Hegstad E, Rosales R, Harklau L, Solhaug JH, Faye RS, Soreide O, Fodstad O (2002) Immunomagnetic detection of micrometastatic cells in bone marrow of colorectal cancer patients. Clin Cancer Res 8: 444-449

Flatmark K, Borgen E, Nesland JM, Rasmussen H, Johannessen HO, Bukholm I, Rosales R, Harklau L, Jacobsen HJ, Sandstad B, Boye K, Fodstad O (2011) Disseminated tumour cells as a prognostic biomarker in colorectal cancer. Br J Cancer 104: 1434-1439

Flatmark K, Mælandsmo GM, Mikalsen SO, Nustad K, Varaas T, Rasmussen H, Meling GI, Fodstad O, Paus E (2004) Immunofluorometric assay for the metastasis-related protein S100A4: release of S100A4 from normal blood cells prohibits the use of S100A4 as a tumor marker in plasma and serum. Tumour Biol 25: 31-40

Grotterød I, Mælandsmo GM, Boye K (2010) Signal transduction mechanisms involved in S100A4-induced activation of the transcription factor NF-kappaB. BMC Cancer 10: 241

Hagemann T, Wilson J, Kulbe H, Li NF, Leinster DA, Charles K, Klemm F, Pukrop T, Binder C, Balkwill FR (2005) Macrophages induce invasiveness of epithelial cancer cells via NF-kappa B and JNK. J Immunol 175: 1197-1205

Han ZD, He HC, Bi XC, Qin WJ, Dai QS, Zou J, Ye YK, Liang YX, Zeng GH, Zhu G, Chen ZN, Zhong WD (2010) Expression and clinical significance of CD147 in genitourinary carcinomas. J Surg Res 160: 260-267

Hilska M, Roberts PJ, Collan YU, Laine VJ, Kossi J, Hirsimaki P, Rahkonen O, Laato M (2007) Prognostic significance of matrix metalloproteinases$1,-2,-7$ and -13 and tissue inhibitors of metalloproteinases-1, -2, -3 and -4 in colorectal cancer. Int J Cancer 121: 714-723

Ingebrigtsen VA, Boye K, Tekle C, Nesland JM, Flatmark K, Fodstad O (2012) B7-H3 expression in colorectal cancer: nuclear localization strongly predicts poor outcome in colon cancer. Int J Cancer; e-pub ahead of print 2 April 2012; doi:10.1002/ijc.27566
Jin JS, Wu CY, Lin YF, Wang JY, Yu CP, Sheu LF, Chiang H, Tsai WC, Lee WH (2006) Higher expression of epidermal growth factor receptor is associated with extracellular matrix metalloprotease inducer in colorectal adenocarcinoma: tissue microarray analysis of immunostaining score with clinicopathological parameters. Dis Markers 22: 309-316

Jung EJ, Lee JH, Min BW, Kim YS, Choi JS (2011) Clinicopathologic significance of fascin, extracellular matrix metalloproteinase inducer, and ezrin expressions in colorectal adenocarcinoma. Indian J Pathol Microbiol 54: 32-36

Klein CA, Seidl S, Petat-Dutter K, Offner S, Geigl JB, Schmidt-Kittler O, Wendler N, Passlick B, Huber RM, Schlimok G, Baeuerle PA, Riethmuller G (2002) Combined transcriptome and genome analysis of single micrometastatic cells. Nat Biotechnol 20: 387-392

Laurie JA, Moertel CG, Fleming TR, Wieand HS, Leigh JE, Rubin J, McCormack GW, Gerstner JB, Krook JE, Malliard J, Twito DI, Morton RF, Tschetter LK, Barlow JF for the North Central Cancer Treatment Group and the Mayo Clinic (1989) Surgical adjuvant therapy of largebowel carcinoma: an evaluation of levamisole and the combination of levamisole and fluorouracil. The North Central Cancer Treatment Group and the Mayo Clinic. J Clin Oncol 7: 1447-1456

Li Y, Xu J, Chen L, Zhong WD, Zhang Z, Mi L, Zhang Y, Liao CG, Bian HJ, Jiang JL, Yang XM, Li XY, Fan CM, Zhu P, Fu L, Chen ZN (2009) HAb18G (CD147), a cancer-associated biomarker and its role in cancer detection. Histopathology 54: 677-687

Moertel CG, Fleming TR, Macdonald JS, Haller DG, Laurie JA, Goodman PJ, Ungerleider JS, Emerson WA, Tormey DC, Glick JH, Veeder MH, Mailliard JA (1990) Levamisole and fluorouracil for adjuvant therapy of resected colon carcinoma. $N$ Engl J Med 322: 352-358

Murray GI, Duncan ME, O’Neil P, Melvin WT, Fothergill JE (1996) Matrix metalloproteinase-1 is associated with poor prognosis in colorectal cancer. Nat Med 2: 461-462

O'Connell JB, Maggard MA, Ko CY (2004) Colon cancer survival rates with the new American Joint Committee on Cancer sixth edition staging. J Natl Cancer Inst 96: 1420-1425

Reimers N, Zafrakas K, Assmann V, Egen C, Riethdorf L, Riethdorf S, Berger J, Ebel S, Janicke F, Sauter G, Pantel K (2004) Expression of extracellular matrix metalloproteases inducer on micrometastatic and primary mammary carcinoma cells. Clin Cancer Res 10: 3422-3428

Riethdorf S, Reimers N, Assmann V, Kornfeld JW, Terracciano L, Sauter G, Pantel K (2006) High incidence of EMMPRIN expression in human tumors. Int J Cancer 119: 1800-1810

Saleem M, Kweon MH, Johnson JJ, Adhami VM, Elcheva I, Khan N, Bin Hafeez B, Bhat KM, Sarfaraz S, Reagan-Shaw S, Spiegelman VS, Setaluri $\mathrm{V}$, Mukhtar H (2006) S100A4 accelerates tumorigenesis and invasion of human prostate cancer through the transcriptional regulation of matrix metalloproteinase 9. Proc Natl Acad Sci USA 103: 14825-14830

Schmidt-Hansen B, Ornas D, Grigorian M, Klingelhofer J, Tulchinsky E, Lukanidin E, Ambartsumian N (2004) Extracellular S100A4(mts1) stimulates invasive growth of mouse endothelial cells and modulates MMP-13 matrix metalloproteinase activity. Oncogene 23: 5487-5495

Sidhu SS, Nawroth R, Retz M, Lemjabbar-Alaoui H, Dasari V, Basbaum C (2010) EMMPRIN regulates the canonical Wnt/beta-catenin signaling pathway, a potential role in accelerating lung tumorigenesis. Oncogene 29: 4145-4156

Sienel W, Polzer B, Elshawi K, Lindner M, Morresi-Hauf A, Vay C, Eder F, Passlick B, Klein CA (2008) Cellular localization of EMMPRIN predicts prognosis of patients with operable lung adenocarcinoma independent from MMP-2 and MMP-9. Mod Pathol 21: 1130-1138

Stein U, Arlt F, Walther W, Smith J, Waldman T, Harris ED, Mertins SD, Heizmann CW, Allard D, Birchmeier W, Schlag PM, Shoemaker RH (2006) The metastasis-associated gene S100A4 is a novel target of betacatenin/T-cell factor signaling in colon cancer. Gastroenterology 131: 1486-1500

Tang Y, Nakada MT, Kesavan P, McCabe F, Millar H, Rafferty P, Bugelski P, Yan L (2005) Extracellular matrix metalloproteinase inducer stimulates tumor angiogenesis by elevating vascular endothelial cell growth factor and matrix metalloproteinases. Cancer Res 65: 3193-3199

Valastyan S, Weinberg RA (2011) Tumor metastasis: molecular insights and evolving paradigms. Cell 147: 275-292

van der Jagt MF, Wobbes T, Strobbe LJ, Sweep FC, Span PN (2009) Metalloproteinases and their regulators in colorectal cancer. J Surg Oncol 101: 259-269 
Yan L, Zucker S, Toole BP (2005) Roles of the multifunctional glycoprotein, emmprin (basigin; CD147), in tumour progression. Thromb Haemost 93: 199-204

Zheng HC, Wang W, Xu XY, Xia P, Yu M, Sugiyama T, Takano Y (2011) Up-regulated EMMPRIN/CD147 protein expression might play a role in colorectal carcinogenesis and its subsequent progression without an alteration of its glycosylation and mRNA level. J Cancer Res Clin Oncol 137: 585-596

Zucker S, Hymowitz M, Rollo EE, Mann R, Conner CE, Cao J, Foda HD, Tompkins DC, Toole BP (2001) Tumorigenic potential of extracellular matrix metalloproteinase inducer. Am J Pathol 158: $1921-1928$

This work is published under the standard license to publish agreement. After 12 months the work will become freely available and the license terms will switch to a Creative Commons Attribution-NonCommercial-Share Alike 3.0 Unported License. 